\title{
JPUR
}

\section{HEALTH AND HUMAN SCIENCES}

\section{Evacuation Behavior of Tōhoku Earthquake and Tsunami Survivors}

Student researcher: Ishra Noor, Senior

Since 2007, the world experienced unparalleled damage from natural hazards. Although earthquakes and flooding are natural phenomena, the severity and frequency of these events are projected to increase as the climate continues to change. It is possible, however, to mitigate the risk of disaster by strong emergency planning; thus it is now more important than ever to study resilience.

On March 11, 2011, the magnitude 9.0 Tōhoku earthquake caused a tsunami that killed over 18,000 people. The event remains the largest recorded earthquake in Japan, and horrified the unprepared residents of Watari, a town in Japan's Miyagi Prefecture. Despite various warnings, the residents responded in ways that often strayed from official expectations. Some individuals were rescued, others fled based on a variety of factors.

Since the 2011 disaster, Watari town officials revamped their emergency plan in preparation for future large tsunamis. This interdisciplinary research focuses on identifying those influential evacuation variables. Information was gathered from personal interviews from some 60 Watari survivors and their individual evacuation routes. Using Google Earth and Harvard's Interactive JapanMap, we produced a digitized evacuation route map and extracted important geographical variables. Initial results indicate that an overwhelming majority of evacuees relied on cars and that certain roads were popular. Other variables, such as alarm quality and distance from the coast, are currently being analyzed. Understanding these relationships from the Tōhoku event can help us detect weaknesses in the town's plan and give us new insight to improve resilience.

Research advisor Daniel P. Aldrich writes, "Ishra Noor's paper tackles a really important question: why do some people evacuate quickly and safely from vulnerable areas, while other people do not? She uses a new data set on the behavior of some 60 people living in the town of Watari-cho in the Tōhoku region of Japan. These people faced a tremendous hazard: a 60-foot tsunami which approached Japan at some 500 miles per hour. Using interviews, GPS data, and category analysis, Ishra sheds light on the factors affecting disaster evacuation behavior."

Noor, I. (2015). Evacuation behavior of Tōhoku earthquake and tsunami survivors. Journal of Purdue Undergraduate Research, 5, 100-101. http://dx.doi.org/10.5703/1288284315682 